\title{
Haemato-biochemical and blood gas changes in bovines under multimodal anaesthesia\#
}

\author{
M. K. Praveen*1, K. D. John Martin², Sudheesh S. Nair ${ }^{3}$, \\ Reji Varghese ${ }^{4}$ and Suresh N. Nair ${ }^{5}$ \\ Department of Veterinary Surgery and Radiology \\ College of Veterinary and Animal Sciences, Mannuthy, Thrissur-680651, \\ Kerala Veterinary and Animal Sciences University, Kerala, India.
}

Citation: Praveen M. K., John Martin, K.D., Sudheesh S. N., Reji, V. and Suresh N. N. 2021. Haemato-biochemical and blood gas changes in bovines under multimodal anaesthesia. J. Vet. Anim. Sci. 52(4): 383-388

DOI: https://doi.org/10.51966/jvas.2021.52.4.383-388

Received: 09.03.2021

Accepted: 09.04.2021

Published: 15.012 .2021

\begin{abstract}
The study was conducted in six crossbred female cattle aged nine months to five years and weighing between 82-375 kg, to evaluate haematobiochemical and blood gas changes in during multimodal general anaesthesia. The animals were premedicated by intravenous administration of butorphanol $(0.05 \mathrm{mg} / \mathrm{kg}$ body weight) immediately followed by xylazine $(0.02 \mathrm{mg} / \mathrm{kg}$ body weight). On achieving sedation, the animals were controlled in left lateral recumbency and induction of anaesthesia was carried out by intravenous administration of ketamine and midazolam at the dose rate of 4.0 and $0.2 \mathrm{mg} / \mathrm{kg}$ body weight respectively. Endotracheal intubation was performed and maintenance of general anaesthesia was carried out using isoflurane in $100 \%$ oxygen. The variation in total erythrocyte count, total leukocyte count, volume of packed red cells, platelet count and haemoglobin were non-significant before and after anaesthesia. A non-significant lymphocytopaenia with neutrophilia and mild variations in aspartate aminotransferase and alanine aminotransferase enzyme levels were also noticed. Blood $\mathrm{pH}$ reduced significantly $(p<0.05)$ after induction of anaesthesia and returned to baseline values after recovery whereas $P v C O_{2}(p<0.05)$ and base excess $(p<0.01)$ values increased significantly after induction of anaesthesia. The blood bicarbonate did not alter significantly following induction of anaesthesia.
\end{abstract}

Keywords: Multimodal anaesthesia, blood gas changes

Running title: Haemato-chemical changes in bovines under multimodal anaesthesia

"Part of M.V.Sc. thesis submitted by the first author to the Kerala Veterinary and Animal Sciences University, Pookode, Wayanad, Kerala

1. M.V.Sc. scholar and *Corresponding author email: praveen.mk6969@gmail.com Ph.9731426631

2. Professor and Head

3. Assistant Professor

4. Assistant Professor, Teaching Veterinary Clinical Complex

5. Assistant Professor, Department of Veterinary Pharmacology and Toxicology

Copyright: () 2021 Praveen et al. This is an open access article distributed under the terms of the Creative Commons Attribution 4.0 International License (http://creativecommons.org/licenses/by/4.0/), which permits unrestricted use, distribution, and reproduction in any medium, provided the original author and source are credited. 
Maintenance of anaesthesia with inhalant anaesthetics in ruminants is considered to be superior to injectable techniques, with respect to safety and early recovery (Cantalapiedra et al., 2000). The level of analgesia provided by inhalant anaesthesia can be improved by inclusion of drugs like opioids such as butorphanol which is an opioid agonist-antagonist and has good sedative and analgesic properties. Ketamine, though an excellent agent for induction of anaesthesia, causes tonic - clonic seizure like activity when used without preanaesthetic sedation. Addition of $a_{2}$ adrenoreceptor agonists like xylazine in the anaesthetic protocol is found to overcome this and enhance sedation, analgesia and muscle relaxation. Midazolam, a short acting benzodiazepine, when administered with ketamine reported to result in better muscle relaxation and analgesia than xylazine with less cardiopulmonary side effects in clinical setting. Combination of $a_{2}$ agonist with opioid could provide reliable and uniform sedation (Malik et al., 2011). A balanced anaesthesia by combination of these four drugs is more beneficial as the dosage of individual drugs can be reduced and hence the toxicity. The effect of these drugs on haematobiochemical and blood gas parameters during general anaesthesia in adult cattle is reported.

\section{Materials and methods}

Six crossbred female cattle aged nine months to five years with body weight ranging from $82-375 \mathrm{~kg}$ were subjected to elective surgical procedures. All the animals were numbered I to $\mathrm{VI}$ and were subjected to standard preanaesthetic preparation. Food was withheld for 24 hours and water for 12-18 hrs prior to surgery. The animals underwent surgical procedures such as herniorrhaphy with onlay grafting (animal I), excision of interdigital fibroma (animal II), transfixation pinning (animal
III), excision of cutaneous mass (animal IV) and umbilical herniorrhaphy (animals $\mathrm{V}$ and $\mathrm{VI}$ ).

The combination of inj.xylazine ${ }^{1}$ and inj.butorphanol ${ }^{2}$ were administered as premedicants at the dose rate of 0.02 and 0.05 $\mathrm{mg} / \mathrm{kg}$ bodyweight respectively intravenously.

Once the sedation was achieved, the animals were controlled in left lateral recumbency and induction of anaesthesia was carried out by intravenous administration of Inj.ketamine ${ }^{2}(4.0 \mathrm{mg} / \mathrm{kg}$ body weight) immediately followed by Inj.midazolam ${ }^{2}$ (0.2 $\mathrm{mg} / \mathrm{kg}$ body weight). Upon the induction of anaesthesia, the trachea was intubated with a cuffed endotracheal tube of appropriate size and was connected to semi closed circuit of a large animal anaesthetic machine ${ }^{2}$ and the anaesthesia was maintained with isoflurane ${ }^{2}$ $(2-4 \%)$ in $100 \%$ oxygen. The onset of sedation was appreciated by symptoms viz; reduced alertness, lowering of head, drooping of eyelids, salivation and in coordinated gait.

The animals, from premedication to recovery from anaesthesia, were monitored by observing physiological and anaesthetic parameters at 15 minute interval. Blood samples were collected before administration of preanaesthetics and after recovery from anaesthesia and were subjected to estimation of haematological parameters viz; total erythrocyte count (TEC), total leukocyte count (TLC), differential leukocyte count (DLC), haemoglobin concentration $(\mathrm{Hb})$, platelet count (PLT) and volume of packed red cells (VPRC) and serum biochemical parameters viz; alanine aminotransferase (ALT) and aspartate aminotransferase (AST) were also studied. Venous blood was collected in heparinized vials viz. before premedication, after induction of anaesthesia, 15 minutes after commencement of isoflurane anaesthesia and after recovery for

\footnotetext{
6. Inj. xylazine - Indian Immunologicals Ltd. Hyderabad, Telangana

7. Inj. butorphanol - Neon Laboratories Ltd. Mumbai

8. Inj. ketamine - Troikaa Pharmaceuticals Ltd. Ahmedabad, Gujarat

9. Inj. midazolam - Troikaa Pharmaceuticals Ltd. Ahmedabad, Gujarat

10. Mallard 2800 C - AB Medical Technologies, USA

11. Isoflurane - Raman and Weil Pvt. Ltd. Mumbai

12. epoc $®$ Blood analysis system - Siemens Healthineers, India
} 
Table 1. Haematological and serum biochemical parameters before and after multimodal anaesthesia in bovine $(n=6)$

\begin{tabular}{|l|c|c|c|c|}
\hline \multicolumn{1}{|c|}{ Parameters } & Before anaesthesia & After anaesthesia & t-value & P-value \\
\hline TLC $(103 / \mu \mathrm{L})$ & $17.75 \pm 2.98$ & $17.02 \pm 2.73$ & $2.125^{\text {ns }}$ & 0.087 \\
\hline TEC $(106 / \mu \mathrm{L})$ & $6.32 \pm 0.23$ & $6.06 \pm 0.4$ & $1.286^{\text {ns }}$ & 0.255 \\
\hline HGB $(\mathrm{g} / \mathrm{dL})$ & $7.35 \pm 0.43$ & $6.92 \pm 0.49$ & $1.06^{\text {ns }}$ & 0.338 \\
\hline VPRC\% & $22.13 \pm 1.85$ & $21.3 \pm 2.39$ & $0.758^{\text {ns }}$ & 0.483 \\
\hline PLT $(103 / \mu \mathrm{L})$ & $371.83 \pm 33.18$ & $364.5 \pm 22.37$ & $0.458^{\text {ns }}$ & 0.666 \\
\hline LYM\% & $64.63 \pm 6.99$ & $62.75 \pm 8.53$ & $0.576^{\text {ns }}$ & 0.589 \\
\hline MON\% & $3.65 \pm 0.62$ & $3.9 \pm 1.12$ & $0.401^{\text {ns }}$ & 0.705 \\
\hline GRA\% & $31.82 \pm 6.48$ & $32.45 \pm 8.17$ & $0.152^{\text {ns }}$ & 0.885 \\
\hline ALT $(\mathrm{IU} / \mathrm{L})$ & $30.12 \pm 2.97$ & $31.36 \pm 3.35$ & $1.192^{\text {ns }}$ & 0.287 \\
\hline AST $(\mathrm{IU} / \mathrm{L})$ & $73.66 \pm 10.62$ & $77.66 \pm 14.06$ & $0.949^{\text {ns }}$ & 0.386 \\
\hline
\end{tabular}

Analysis done by students ' $t$ ' test using SPSS version 24.0 ns Non-Significant $(P>0.05)$

Table 2. Changes in blood gas parameters during different stages of multimodal anaesthesia in cattle $(n=6)$.

\begin{tabular}{|l|c|c|c|c|c|}
\hline \multicolumn{1}{|c|}{ Parameters } & $\begin{array}{c}\text { Before } \\
\text { induction }\end{array}$ & $\begin{array}{c}\text { After induction } \\
\text { of GA }\end{array}$ & $\begin{array}{c}\text { 15mins after } \\
\text { ET intubation }\end{array}$ & After recovery & $\begin{array}{c}\text { F-value } \\
\text { (P-value) }\end{array}$ \\
\hline $\mathrm{pH}$ & $7.52 \pm 0.05^{\mathrm{a}}$ & $7.42 \pm 0.03^{\mathrm{ab}}$ & $7.40 \pm 0.02^{\mathrm{b}}$ & $7.51 \pm 0.04^{\mathrm{ab}}$ & $\begin{array}{c}3.916^{\star} \\
(0.030)\end{array}$ \\
\hline $\mathrm{pCO}(\mathrm{mmHg})$ & $35.02 \pm 2.95^{\mathrm{b}}$ & $43.93 \pm 3.39^{\mathrm{ab}}$ & $48.02 \pm 2.78^{\mathrm{a}}$ & $34.97 \pm 4.36^{\mathrm{ab}}$ & $\begin{array}{c}4.166^{\star} \\
(0.025)\end{array}$ \\
\hline $\mathrm{pO} 2(\mathrm{mmHg})$ & $116.35 \pm 19.2$ & $113.28 \pm 23.26$ & $119.4 \pm 13.19$ & $89.05 \pm 24.89$ & $\begin{array}{c}0.622^{\mathrm{ns}} \\
(0.612\end{array}$ \\
\hline $\mathrm{cHCO}(\mathrm{mmol} / \mathrm{L})$ & $23.4 \pm 2.93$ & $28.28 \pm 0.45$ & $30.45 \pm 0.75$ & $28.98 \pm 0.80$ & $\begin{array}{c}4.120^{\mathrm{ns}} \\
(0.077)\end{array}$ \\
\hline $\mathrm{BE}(\mathrm{ecf})(\mathrm{mmol} / \mathrm{L})$ & $2.90 \pm 0.37^{\mathrm{c}}$ & $4.05 \pm 0.16^{\mathrm{b}}$ & $5.75 \pm 0.83^{\mathrm{ab}}$ & $6.50 \pm 0.46^{\mathrm{a}}$ & $\begin{array}{c}10.093^{\star \star} \\
(0.004)\end{array}$ \\
\hline
\end{tabular}

Analysis done by repeated measures ANOVA followed by Least Significant Difference method using SPSS version 24.0

${ }^{*}$ Significant at 0.01 level $(P<0.01)$; * Significant at 0.05 level $(P<0.05)$; $n s$ Non-Significant $(P>0.05)$

Means having different letter as superscript differ significantly within a row

estimation of blood gas parameters like blood $\mathrm{pH}$, partial pressure of carbon dioxide, partial pressure of oxygen, blood bicarbonate and base excess values using automatic blood gas analyser ${ }^{1}$. The changes in haematobiochemical and blood gas parameters during the anaesthesia were analysed statistically.

\section{Results and discussion}

The mean total erythrocyte count $(10 \% / \mu \mathrm{L})$ was $6.32 \pm 0.23$ and $6.06 \pm 0.4$ before administration of preanaesthetics and after recovery from anaesthesia respectively (Table 1). TEC values reduced non-significantly after anaesthesia. The finding was in agreement with that of Hikasa et al. (2000) in sheep and Muchalambe et al. (2020) in cattle. The mean total leukocyte count $\left(10^{3} / \mu \mathrm{L}\right)$ among animals decreased non-significantly after recovery than that before anaesthesia and was $17.75 \pm 2.98$ and $17.02 \pm 2.73$ respectively (Table 1 ). The decrease in leukocyte count after anaesthesia could be attributed to ketamine administration (Cullen and Van Belle, 1975). The TLC values were elevated which could be due to preexisting subclinical infection. The mean value of haemoglobin concentration $(\mathrm{g} / \mathrm{dL})$ was $7.35 \pm$ 0.43 and $6.92 \pm 0.49$, the mean value of platelet count $\left(10^{3} / \mu \mathrm{L}\right)$ was $371.83 \pm 33.18$ and $364.5 \pm$ 22.37 and the mean volume of packed red cells (\%) was $22.13 \pm 1.85$ and $21.3 \pm 2.39$ before 
administration of pre anaesthetics and after recovery from anaesthesia respectively (Table 1). The decrease in haematocrit, platelet count and haemoglobin values observed on recovery from anaesthesia was not significant when compared to pre surgical values. Kilic (2008) reported significant decrease in haemoglobin concentration in calves after detomidine midazolam - ketamine anaesthesia. Kumar et al. (2014) also made a similar observation with ketamine-midazolam anaesthesia in buffalo calves. Muchalambe et al. (2020) reported significant decrease in haemoglobin and platelet concentration upon administration of midazolam - propofol and xylazine - propofol combinations as induction agents for isoflurane anaesthesia in cattle. Decrease in VPRC was reported following xylazine administration in calves (Picavet et al., 2004) and in goat (Ahmad and Shukla, 2011) and with isoflurane anaesthesia in sheep (Hikasa et al., 2000). Kilic (2008) and Muchlambe et al. (2020) attributed the decreased fluid shift to the intravascular compartment from extravascular compartment to maintain normal cardiac output as the cause for reduction in haematocrit values. Pooling of circulatory blood cells in the spleen due to decreased sympathetic activity could be another cause for reduced packed cell volume, total erythrocyte count, total leukocyte count, platelet count and haemoglobin (Kilic, 2008). However the $\mathrm{Hb}$ and VPRC values were below the normal physiological range before and after anaesthesia, which could be attributed to the history of haemoprotozoan infection in two cattle under the study.

The mean lymphocytes count (\%) was $64.63 \pm 6.99$ and $62.75 \pm 8.53$ at the two observations respectively. The mean granulocytes count (\%) was $31.82 \pm 6.48$ and $32.45 \pm 8.17$ and mean monocytes count (\%) was $3.65 \pm 0.62$ and $3.9 \pm 1.12$ before administration of pre anaesthetics and after recovery from anaesthesia, respectively (Table 1). Lymphocytopaenia along with granulocytophilia observed after anaesthesia in the present study was non-significant which could be attributed to the stress caused by administration of pre medicants and induction agents followed by stimulation of adrenal gland (Singh et al., 2013).
Serum alanine aminotransferase and aspartate aminotransferase exhibited insignificant increase before and after anaesthesia. The mean value of alanine amino-transferase level $(\mathrm{IU} / \mathrm{L})$ was $30.12 \pm 2.97$ and $31.36 \pm 3.35$ and aspartate aminotransferase (IU/L) was $73.66 \pm$ 10.62 and $77.66 \pm 14.06$ before administration of pre anaesthetics and after recovery from anaesthesia respectively (Table 1). Lower blood circulation to the liver after administration of anaesthetics could be the cause for nonsignificant increase in liver enzymes after anaesthesia (Malik and Singh, 2007).

The mean blood pH among the studied animals were $7.52 \pm 0.05,7.42 \pm 0.03,7.40 \pm$ 0.02 and $7.51 \pm 0.04$ before premedication, after induction of anaesthesia, 15 minutes after commencement of isoflurane anaesthesia and after recovery from anaesthesia respectively (Table 2). A significant $(p<0.05)$ decrease in $\mathrm{pH}$ following induction and commencement of isoflurane anaesthesia was noticed which could be due to respiratory depression and subsequent respiratory acidosis (Benato et al., 2013). Significant decrease in arterial $\mathrm{pH}$ was noticed in calves by Picavet et al. (2004) and Kilic (2008) following xylazine - guaiphenesin ketamine and dexmedetomidine - midazolam ketamine anaesthesia respectively. Harmanjeet et al. (2013) also observed significant reduction in blood $\mathrm{pH}$ in buffaloes under general anaesthesia. The $\mathrm{pH}$ value was marginally elevated above the normal physiological limit before the anaesthesia and fluctuated within the normal limits during the anaesthesia.

The mean blood $\mathrm{P}_{\mathrm{v}} \mathrm{CO}_{2}(\mathrm{mmHg})$ in the study was $35.02 \pm 2.95,43.93 \pm 3.39,48.02 \pm$ 2.78 and $34.97 \pm 4.36$ before premedication, after induction of anaesthesia, 15 minutes after commencement of isoflurane anaesthesia and after recovery from anaesthesia respectively(Table 2). A significant increase $(p<0.05)$ in $\mathrm{PvCO}_{2}$ was noticed after induction of anaesthesia and commencement of isoflurane anaesthesia from the baseline values in the present study. Similar changes in $\mathrm{PaCO}_{2}$ values were reported by Hikasa et al. (2000) in sheep, Harmanjeet et al. (2013) in buffaloes, Capak et al. (2017) in dogs. Hypercapnia observed in the present could be due to alveolar 
hypoventilation and positioning of the animals during surgical procedure (Benato et al. 2013). The mean blood $\mathrm{P}_{\mathrm{v}} \mathrm{O}_{2}(\mathrm{mmHg})$ was $116.35 \pm$ $19.2,113.28 \pm 23.26,119.4 \pm 13.19$ and 89.05 \pm 4.89 before premedication, after induction of anaesthesia, 15 minutes after commencement of isoflurane anaesthesia and after recovery from anaesthesia respectively (Table 2). Even though there was a drastic reduction after the recovery, it was not significant statistically. The decrease in $\mathrm{P}_{v} \mathrm{O}_{2}$ values after induction of anaesthesia may be due to the pressure on diaphragm by viscera while placing the animal on lateral recumbency. The increase in the $\mathrm{P}_{v} \mathrm{O}_{2}$ values fifteen minutes following commencement of isoflurane anaesthesia observed in this study may be due to the high concentration of oxygen inspired from the fresh gas supply provided after intubation. These observations were in agreement with those made by Picavet et al. (2004). The $\mathrm{P}_{\mathrm{v}} \mathrm{O}_{2}$ value was decreased after extubation, probably due to withdrawal of the oxygen on weaning from the anaesthesia machine.

The mean blood $-\mathrm{cCHO}_{3}(\mathrm{mmol} / \mathrm{L})$ was $23.4 \pm 2.93,28.28 \pm 0.45,30.45 \pm 0.75$ and $28.98 \pm 0.80$ before premedication, after induction of anaesthesia, 15 minutes after commencement of isoflurane anaesthesia and after recovery from anaesthesia respectively (Table 2). The variations were not significant statistically though slight elevation was noticed during post induction of anaesthesia upto recovery. The increase in bicarbonate values noticed during the anaesthesia could be a compensatory mechanism to mitigate the respiratory acidosis caused by increase in $\mathrm{P}_{\mathrm{v}} \mathrm{CO}_{2}$ (Benato et al., 2013).

The mean blood base excess (ecf) $(\mathrm{mmol} / \mathrm{L})$ was $2.90 \pm 0.37,4.05 \pm 0.16,5.75$ \pm 0.83 and $6.50 \pm 0.46$ before premedication, after induction of anaesthesia, 15 minutes after commencement of isoflurane anaesthesia and after recovery from anaesthesia respectively. There was asignificant increase $(p<0.01)$ in base excess value after induction of anaesthesia. However the increase was well within the normal physiologic range. The findings of the present study were in contradiction with observations made by Picavet et al. (2004) who observed non-significant increase in base excess value in calves. The increase in base excess values could be due to respiratory acidosis caused by an increase in $\mathrm{P}_{\mathrm{v}} \mathrm{CO}_{2}$ value during anaesthetic maintenance (Benato et al., 2013).

\section{Conclusion}

In the present study, the haematological, serum biochemical and blood gas parameters were within the normal range, suggesting that the anaesthetic combinations used in the present study did not produce any adverse effect on body systems.

\section{Acknowledgement}

The authors are thankful to authorities of Kerala Veterinary and Animal Sciences University for providing all facilities for the completion of this work.

\section{Conflict of interest}

The authors declare that they have no conflict of interest.

\section{References}

Ahmad, R. and Shukla, B. P. 2011. Studies on clinico-physiological and haematobiochemical changes following epidural analgesia by ropivacaine and ropivacaine-xylazine combination in goats. Vet. Pract. 12: 171-174.

Benato, L., Chesnel, M., Eatwell, K. and Meredith, A. 2013. Arterial blood gas parameters in pet rabbits anaesthetized using a combination of fentanyl fluanisone - midazolam - isoflurane. J. Small Anim. Pract. 54: 343-346.

Cantalapiedra, A. G., Villanueva, B. and Pereira, J. L. 2000. Anesthetic potency of isoflurane in cattle: determination of the minimum alveolar concentration. Vet. Anaesth. Analg. 27: 22-26.

Capak, H., Filipović-Genter, Z., Nesek-Adam, V., Vince, S., Solina, S., Milas, D. and Capak, D. 2017. Acid-base balance during volatile and total intravenous anaesthesia in dogs. Vet. Arh. 87: 281289. 
Cullen, B. F. and Van Belle, G. 1975. Lymphocyte transformation and changes in leukocyte count: effects of anesthesia and operation. J.Am.Soc. Anesthesiologists. 43: 563-568.

Harmanjeet, S., Tarunbir, S., Raghunath, M., Mohindroo, J., Pallavi, V., Saini, N. S. and Singh, S. S. 2013. Blood gas, acid base and electrolyte changes during diazepam, midazolam premedication and halothane anaesthesia in buffaloes subjected to diaphragmatic herniorrhaphy. Indian J. Anim. Sci. 83: 693-696.

Hikasa, Y., Saitob, K., Takaseb, K. and Ogasawara, S. 2000. Clinical, cardiopulmonary, haematological and serum biochemical effects of sevoflurane and isoflurane anesthesia in oxygen under spontaneous breathing in sheep. Small Rumin. Res. 36: 241-249.

Kilic, N. 2008. Cardiopulmonary, biochemical and haematological changes after detomidine-midazolam-ketamine anesthesia in calves. Bull. Vet. Inst. Pulawy. 52: 453-456.

Kumar, A., Kumar, A., Singh, S. and Chaudhary, R.N. 2014. Evaluation of midazolamketamine as anaesthetic combination in buffalo calves. Haryana Vet. 53: 117120.

Malik V, Singh B. 2007. Clinical and
haematobiochemical studies on ketamine and its combinations with diazepam, midazolam and xylazine for general anesthesia in horses. Indian $J$ Vet. Surg. 28: 23-26.

Malik, V., Kinjavdekar, P., Amarpal, Aithal, H. P., Pawde, A. M. and Surbhi. 2011. Comparative evaluation of halothane anesthesia in medetomidinebutorphanolandmidazolam-butorphanol premedicated water buffaloes (Bubalus bubalis). S. Afr. Vet. Ver. 82: 8-17.:

Muchalambe, B., Dilipkumar, D. and Venkatgiri. 2020. Heamato-biochemical evaluation of midazolam-propofol and xylazinepropofol induction combinations for isoflurane anaesthesia in cattle. $J$. Entomol. Zool. Stud. 8: 997-1001.

Picavet, M. T. J., Gasthuys, F.M., Laevens, H. H. and Watts, S.A. 2004. Cardiopulmonary effects of combined xylazineguaiphenesin-ketamine infusion and extradural (inter-coccygeal lidocaine) anaesthesia in calves. Vet. Anaesth. Analg. 31: 11-19.

Singh, G. D., Kinjavdekar, P., Amarpal, Aithal, H. P., Pawde, A. M. and Zama, M. M. 2013. Clinicophysiological and haemodynamic effects of fentanyl with xylazine, medetomidine and dexmedetomidine in isoflurane-anesthetized water buffaloes (Bubalus bubalis). J. S. Afr. Vet. Assoc. 84: 67-77. 